\title{
Desempenho de juvenis de jundiás (Rhamdia voulezi) submetidos à alimentação com ração orgânica certificada e comercial
}

\author{
Performance of silver catfish (Rhamdia voulezi) juveniles fed with \\ certified organic and commercial ration
}

\author{
Aldi Feiden ${ }^{[a]}$, Arcângelo Augusto Signor ${ }^{[b]}$, Odair Diemer ${ }^{[c]}$, Cesar Sary ${ }^{[\mathrm{d}]}$, \\ Wilson Rogério Boscolo ${ }^{[\mathrm{e}]}$, Dacley Hertes Neu ${ }^{[\mathrm{f}]}$
}

[a] Engenheiro agrônomo, Doutor em Ecologia de Ambientes Aquáticos Continentais, professor adjunto da Universidade Estadual do Oeste do Paraná (UNIOESTE), Toledo, PR - Brasil, e-mail: feiden@seti.pr.gov.br

[b] Engenheiro de pesca, Doutorando em Zootecnia pela Universidade Estadual de Maringá (UEM), pesquisador do Instituto Água Viva, Toledo, PR - Brasil, e-mail: angelo_signor@hotmail.com

[c] Engenheiro de pesca, Mestrando em Zootecnia pela Universidade Estadual do Oeste do Paraná (UNIOESTE), pesquisador do Instituto Água Viva, Toledo, PR - Brasil, e-mail: odairdiemer@hotmail.com

[d] Zootecnista, técnico do Centro de Produção e Propagação de Organismos Marinhos (CPPOM) da Pontifícia Universidade Católica do Paraná (PUCPR), Guaratuba, Paraná - Brasil, e-mail: zitozootecnia@hotmail.com

[e] Zootecnista, Doutor em Produção Animal, professor adjunto da Universidade Estadual do Oeste do Paraná (UNIOESTE), Toledo, PR - Brasil, e-mail: wrboscolo@bol.com.br

[f] Engenheiro de pesca, Mestrando em Recursos Pesqueiros e Engenharia de Pesca pela Universidade Estadual do Oeste do Paraná (UNIOESTE), pesquisador do Instituto Água Viva, Toledo, PR - Brasil, e-mail: dacley_pesca@hotmail.com

\section{Resumo}

O presente estudo teve como objetivo avaliar o efeito da alimentação com ração orgânica certificada e comercial no desempenho de jundiás (Rhamdia voulezi) criados em tanques-rede. Foram utilizados 1.080 juvenis de jundiá com peso e comprimento inicial médio de 15,01 \pm 3,32 g e 11,60 $\pm 0,80 \mathrm{~cm}$, respectivamente, distribuídos em um delineamento inteiramente casualizado com dois tratamentos e seis repetições em doze tanques-rede com $0,25 \mathrm{~m}^{3}$ de volume útil e malha de $5 \mathrm{~mm}$. Não foram observadas diferenças $(\mathrm{p}>0,05)$ nos parâmetros zootécnicos. Portanto, a alimentação de jundiás com certificação orgânica não compromete o desempenho produtivo dos peixes e a sua substituição pode ser realizada na produção comercial de juvenis.

Palavras-chave: Nutrição. Alimentação. Produção animal. Ração orgânica. 


\begin{abstract}
The present study aimed to evaluate the effect of organic certified ration and conventional feeding in the performance of silver catfish (Rhamdia voulezi) reared in cages. A total of 1.080 juveniles with initial weight and length of $15,01 \pm 3,32 \mathrm{~g}$ and 11,60 $\pm 0,80 \mathrm{~cm}$, respectively were used distributed in a completely randomized design with two treatments and six replications in twelve cages with $0,25 \mathrm{~m}^{3}$ of usable volume and $0,5 \mathrm{~cm}$ mesh. There were no significantly differences $(p>0,05)$ in zootechnical parameters. Therefore, organic certified feeding to silver catfish does not compromise the fish's productive performance and its replacement can be done in case of a commercial production of juveniles.
\end{abstract}

Keywords: Nutrition. Food. Animal production. Organic feed.

\title{
Introdução
}

Nos últimos anos, a aquicultura teve um considerável aumento na produção de organismos aquáticos dulcícolas. Contudo, o ritmo de crescimento pode aumentar, principalmente em razão das condições hidrográficas que o Brasil apresenta. Segundo Godinho (2007), no Brasil são produzidas comercialmente cerca de 40 espécies de peixes de água doce.

$\mathrm{Na}$ região sul do País, o jundiá tem despertado grande atenção de pesquisadores e produtores de peixes graças às várias características favoráveis para a criação comercial (GOMES et al., 2000), entretanto, essa espécie apresenta 49 sinonímias e necessita de maior compreensão para a elaboração de um pacote zootécnico.

O jundiá é uma espécie pertencente ao gênero Rhamdia, que é formado por 11 espécies, dentre as quais se encontra o Rhamdia voulezi. Segundo Luchini e Avendaño (1985) e Baldisserotto e Radünz Neto (2005), o jundiá é um peixe de rápido crescimento, apresenta fácil adaptação à criação intensiva, rusticidade, facilidade na indução à reprodução, alta taxa de fecundação, possuindo ainda carne saborosa com baixo teor de gordura e com poucas espinhas, além de apresentar boa aceitação no mercado consumidor.

Atualmente, o comércio de alimentos orgânicos é um dos que mais cresce na esfera mundial, em torno de $10 \%$ a $20 \%$ ao ano. Na Europa, a maioria dos governos já divulgou a intenção de converter entre $10 \%$ e $20 \%$ da área agrícola para essa forma de produção. O Brasil é um dos países onde mais cresce a produção orgânica, com um crescimento estimado em 30\% ao ano, ocupando atualmente 6,5 milhões de hectares de terras, compostas por áreas de produção diversificada, colocando o País na segunda posição dentre os maiores produtores mundiais (IPARDES, 2007).

O sistema de cultivo orgânico é voltado para o melhoramento dos ciclos de vida natural preservando a natureza. Baseia-se praticamente nos recursos domésticos disponíveis, em que os agricultores normalmente conhecidos como produtores orgânicos demonstram que seu sistema é diferente dos demais sistemas agrícolas e, acima de tudo, é competitivo, capaz de fornecer produtos agrícolas de boa qualidade, minimizando os efeitos colaterais (ORMOND et al., 2002).

Conforme Michalczyszyn, Giroto e Bortolozo (2008), o mercado consumidor está cada vez mais exigente, e as indústrias estão buscando atendê-lo após operar modificações em suas mercadorias com a finalidade de melhorá-las qualitativamente em disponibilidade dos produtos. Com a utilização de alimentos orgânicos, um novo conceito pode ser aplicado e destinado à parcela da população que se preocupa com a segurança alimentar.

Nesse contexto, a aquicultura é um setor que tem enorme potencial para a produção de proteína animal para o consumo humano por meio do fornecimento de "rações orgânicas", produzindo, assim, carnes com certificação orgânica. Contudo, a produção de rações ainda é bastante limitada graças a peculiaridades que o sistema de produção apresenta, principalmente a difusão das tecnologias disponíveis e os testes de campo em unidades demonstrativas para que os criadores de animais possam ver e comprovar a eficiência e as limitações do sistema de criação de animais orgânicos (DIEMER et al., 2009).

Rev. Acad., Ciênc. Agrár. Ambient., Curitiba, v. 8, n. 4, p. 381-387, out./dez. 2010 
Pela deficiência de informações com relação ao uso de rações orgânicas na alimentação de peixes, o presente trabalho tem por objetivo avaliar o efeito da alimentação com ração orgânica (formulada com base em ingredientes orgânicos) e ração convencional sobre o desempenho de jundiás criados em tanques-rede.

\section{Materiais e métodos}

O experimento foi realizado na área aquícola do reservatório da Usina Hidrelétrica Governador José Richa (Salto Caxias - Rio Iguaçu), localizada no município de Boa Vista da Aparecida, PR, durante um período de 78 dias (maio a julho de 2009).

Foram utilizados 1.080 juvenis com peso e comprimento inicial médio de 15,01 \pm 3,32 g e 11,60 \pm $0,80 \mathrm{~cm}$, respectivamente, distribuídos em um delineamento inteiramente casualizado com dois tratamentos e seis repetições em doze tanques-rede com $0,25 \mathrm{~m}^{3}$ de volume útil e malha de $0,5 \mathrm{~cm}$, sendo a unidade experimental composta por um tanque com 90 peixes.

Os peixes foram alimentados com duas rações experimentais, uma ração formulada com ingredientes certificados de origem orgânica e uma ração convencional, ambas com $36 \%$ de proteína bruta. A composição química dos ingredientes orgânicos e a composição percentual e química da ração estão apresentadas nas Tabelas 1 e 2, respectivamente. As rações foram fornecidas na forma extrusada, quatro vezes ao dia (8h, 11h, 13h e 17h).

Tabela 1 - Composição química dos alimentos (matéria natural)

\begin{tabular}{lccc}
\hline Alimentos & Proteína bruta & Gordura & Matéria mineral \\
\hline Farelo de soja orgânico & 45,126 & 7,755 & 6,417 \\
Trigo integral orgânico & 17,472 & 3,405 & 4,435 \\
Milho orgânico & 5,257 & 4,600 & 1,460 \\
Farinha de resíduo da indústria de filetagem de tilápia ${ }^{1}$ & 50,37 & 21,77 & 18,75 \\
\hline
\end{tabular}

${ }^{1}$ Adaptada de BOSCOLO et al., 2005.

Fonte: Elaboração dos autores.

Tabela 2 - Composição percentual e química da ração orgânica (matéria natural) (continua)

\begin{tabular}{lc}
\hline Ingredientes & $\%$ \\
\hline Farelo de soja orgânico & 35,372 \\
Milho orgânico & 20,00 \\
Trigo integral orgânico & 18,628 \\
Farinha de resíduo da indústria de filetagem & 25,00 \\
de tilápias & 0,700 \\
Suplemento mineral e vitamínico & \\
Sal comum & 0,300 \\
\hline Total & 100,00 \\
\hline
\end{tabular}


Tabela 2 - Composição percentual e química da ração orgânica (matéria natural)

(conclusão)

\begin{tabular}{lc}
\hline Nutrientes & \\
\hline Energia digestível (kcal/kg) & 3200,00 \\
Proteína bruta (\%) & 36,00 \\
Fósforo total (\%) & 0,900 \\
Gordura (\%) & 5,314 \\
Lisina total (\%) & 2,204 \\
Metionina total (\%) & 0,745 \\
Met + cistina total (\%) & 1,295 \\
\hline
\end{tabular}

${ }^{1}$ Composição do Premix. Níveis de garantia por quilograma do produto: Vit. A: 24.000 UI; Vit. D3: 6.000 UI; Vit. E: 300 mg; Vit. K3: 30 mg; Vit. B1: 40 mg; Vit. B2: 40 mg; Vit. B6: 35 mg; Vit. B12: 80 mg; Ác. fólico: $12 \mathrm{mg}$; Pantotenato Ca: $100 \mathrm{mg}$; Vit. C: $600 \mathrm{mg}$; Biotina: $2 \mathrm{mg}$; Colina: 1.000 mg; Niacina; Ferro: 200 mg; Cobre: 35 mg; Manganês: 100 mg; Zinco: $240 \mathrm{mg}$; Iodo: 1,6 mg; Cobalto: 0,8 mg.

Fonte: Elaboração dos autores.

Os parâmetros físicos e químicos da água $-\mathrm{pH}$, oxigênio dissolvido $\left(\mathrm{mg} \cdot \mathrm{L}^{-1}\right)$ e condutividade elétrica $\left(\mu \mathrm{S} \cdot \mathrm{cm}^{-1}\right)$ - foram mensurados semanalmente, utilizando medidores portáteis, enquanto a temperatura $\left({ }^{\circ} \mathrm{C}\right)$ foi aferida diariamente pela manhã (8h30) e à tarde (17h) com auxílio de um termômetro.

Ao final do período experimental, os animais permaneceram em jejum por 24 horas. Posteriormente, coletou-se aleatoriamente nove peixes de cada tanque-rede, insensibilizados por choque térmico, acondicionados em caixa térmica com gelo e transportados ao Laboratório de Tecnologia do Pescado do Grupo de Estudos em Manejo na Aquicultura (GEMAq) localizado na cidade de Toledo, PR.

Foram avaliados os índices zootécnicos de peso final (g), ganho de peso (g) (peso final - peso inicial), comprimento total $(\mathrm{cm})$, conversão alimentar aparente (consumo de ração/ganho de peso), sobrevivência $(\%)$, rendimento de carcaça $[$ peso do peixe eviscerado $(\mathrm{g}) \times 100) /$ peso inteiro $(\mathrm{g})]$, índice hepatossomático $(\%)$ (peso fígado/peso vivo $\times 100)$, gordura visceral $(\mathrm{g})$ e composição química da carcaça dos peixes.

Os resultados obtidos no final do período experimental foram submetidos ao teste t de Student, por meio do programa Microsoft ${ }^{\circledR}$ Excel.

\section{Resultados e discussão}

Os parâmetros físicos e químicos da água dos tanques-rede, temperatura $19,3 \pm 2,1{ }^{\circ} \mathrm{C}$ (manhã) e $20,1 \pm 2,4^{\circ} \mathrm{C}$ (tarde), oxigênio dissolvido 7,43 \pm 0,60 mg.L-1, pH 6,44 \pm 0,35 e condutividade 51,9 \pm 3,1 $\mu$ S.cm-1 ficaram dentro da condição normal para peixes tropicais (ARANA, 2004).

Os resultados de ganho de peso, comprimento total, conversão alimentar, sobrevivência, rendimento de peixe eviscerado, gordura vísceral, índice hepatossomático, proteína bruta, umidade, lipídios e matéria mineral não apresentaram diferença pelo teste $t(p>0,05)$ (Tabela 3).

Sary et al. (2009), analisando as características da carcaça de jundiás (Rhamdia voulez̨) submetidos à alimentação com certificação orgânica e convencional, relataram que a substituição da alimentação comercial pela ração orgânica não compromete as características da carcaça em jundiás criados em tanques-rede. Os autores 
ainda descreveram que os níveis de matéria seca, umidade, proteína bruta, lipídios e matéria mineral dos peixes não diferiram estatisticamente entre os tratamentos, assim como o que foi encontrado no presente trabalho.

Em trabalhos realizados com suínos por Costa et al. (1995), a criação orgânica ao ar livre apresentou-se tecnicamente viável, pois o peso médio dos leitões ao desmame e o número de leitões desmamados por parto foram superiores ao sistema convencional, comprovando que a criação orgânica em alguns casos pode ser superior.

Tabela 3 - Parâmetros referentes ao desempenho de jundiás (R. voulę̧) submetidos à alimentação com ração orgânica e comercial criados em tanques-rede

\begin{tabular}{|c|c|c|c|c|}
\hline \multirow{2}{*}{ Variáveis } & \multicolumn{2}{|c|}{ Rações } & \multirow{2}{*}{ CV (\%) } & \multirow{2}{*}{ Teste $\mathbf{t}$} \\
\hline & Orgânicos & Convencionais & & \\
\hline \multicolumn{5}{|l|}{ Desempenho } \\
\hline Peso final (g) & $52,81 \pm 6,75$ & $55,59 \pm 5,91$ & 11,7 & $0,4657^{\text {ns }}$ \\
\hline Ganho de peso (g) & $37,8 \pm 6,75$ & $40,57 \pm 5,91$ & 16,19 & $0,4657^{\text {ns }}$ \\
\hline Comprimento total $(\mathrm{cm})$ & $16,33 \pm 0,67$ & $16,54 \pm 0,52$ & 3,65 & $0,5568^{\text {ns }}$ \\
\hline Comprimento-padrão (cm) & $13,37 \pm 0,76$ & $13,64 \pm 0,52$ & 4,82 & $0,4837^{\text {ns }}$ \\
\hline Conversão alimentar & $0,93 \pm 0,14$ & $0,8 \pm 0,09$ & 14,02 & $0,1045^{\mathrm{ns}}$ \\
\hline Sobrevivência (\%) & $98,33 \pm 1,69$ & $97,59 \pm 2,66$ & 2,27 & $0,5780^{\text {ns }}$ \\
\hline \multicolumn{5}{|l|}{ Rendimento corporal } \\
\hline Peixe eviscerado (\%) & $88,99 \pm 1,72$ & $88,51 \pm 2,02$ & 2,12 & $0,4817^{\mathrm{ns}}$ \\
\hline Gordura visceral (\%) & $1,84 \pm 0,72$ & $2,24 \pm 0,22$ & 26,34 & $0,2371^{\mathrm{ns}}$ \\
\hline Índice hepatossomático (\%) & $2,44 \pm 0,26$ & $2,37 \pm 0,34$ & 12,84 & $0,7009^{\text {ns }}$ \\
\hline \multicolumn{5}{|l|}{ Composição química } \\
\hline Umidade (\%) & $74,73 \pm 0,57$ & $73,66 \pm 0,33$ & 1,811 & $0,7953^{\text {ns }}$ \\
\hline Proteína bruta (\%) & $15,46 \pm 0,73$ & $15,56 \pm 0,79$ & 4,883 & $0,1052^{\mathrm{ns}}$ \\
\hline Matéria mineral (\%) & $2,94 \pm 0,30$ & $3,03 \pm 0,12$ & 4,409 & $0,4291^{\mathrm{ns}}$ \\
\hline Lipídios (\%) & $6,27 \pm 0,29$ & $7,23 \pm 0,30$ & 7,627 & $0,3477^{\mathrm{ns}}$ \\
\hline
\end{tabular}

Legenda: ns = não significativo a 5\% de significância pelo teste $\mathrm{t}$ de Student.

Fonte: Elaboração dos autores.

Lösch et al. (2009a), avaliando rações com níveis de fósforo à base de alimentos orgânicos e fosfato bicálcico, relatam que a suplementação de farinha de peixe como fonte de fósforo ou a suplementação de $50 \%$ da farinha de peixe e 50\% de fosfato bicálcico em rações orgânicas para juvenis de tilápia do Nilo (Oreochromis niloticus) promovem bom desempenho aos peixes, entretanto a melhor resposta de ganho de peso pode ser explicada graças ao fato da ração com farinha de peixe apresentar maior nível de metionina na dieta.

Os dados obtidos no presente estudo corroboram os de Lazzari et al. (2008), que pesquisaram diferentes fontes proteicas em dietas na fase de recria do jundiá, observando deposição de lipídios, matéria mineral, proteína bruta e matéria seca similares. Segundo Shearer (1994 apud SOUZA et al., 1999), a informação sobre a composição 
bromatológica do peixe e os fatores que afetam suas características permitem com eficiência a determinação da transferência de nutrientes do alimento ao peixe, tornando possível prever transformações na composição da carcaça.

Para alevinos de tilápias do Nilo, Lösch et al. (2009b) não relataram diferenças no desempenho zootécnico dos animais, quando alimentados com rações orgânicas contendo diferentes fontes de fósforo, e concluíram que a ração orgânica pode ser utilizada com eficiência por esses animais.

$\mathrm{Na}$ atual pesquisa, apesar de não ser verificada diferença no desempenho zootécnico dos organismos criados, há a necessidade de estudos relacionados à qualidade nutricional do alimento orgânico. Alguns autores sugerem que esse alimento é superior nutricionalmente quando comparado ao convencional. Corroborando com essa afirmação, o Guia Rural (1991) mostrou que os ovos de galinhas criadas soltas possuem cerca de quatro vezes mais vitamina A quando comparados a ovos de granja. Além disso, o ovo de galinha caipira criada em sistema orgânico não contém resíduos de antibióticos e de outros produtos químicos, pois essas galinhas não estão sujeitas a receber esse tipo de aditivo via ração no sistema orgânico.

Em síntese, no aspecto do valor nutritivo e toxicológico os alimentos provenientes da produção orgânica vegetal e animal têm se mostrado superior aos convencionais. Contudo, é um campo pouco explorado pelas pesquisas científicas que, apesar de não nos permitirem uma unanimidade na evidência da superioridade nutricional dos alimentos orgânicos, nos revela que é imprescindível prevenir quanto ao uso de produtos químicos potencialmente perigosos à saúde.

Segundo estudo publicado em 2007 pelo Ipardes é crescente a produção, a comercialização e o consumo de produtos orgânicos não só no Estado do Paraná, mas também nos âmbitos nacional e mundial. No entanto, com a tendência de aumento na demanda por alimentos orgânicos, o desenvolvimento da criação de peixes no sistema de produção orgânica torna-se uma atraente atividade, além de uma agregação financeira que varia de $30 \%$ a $40 \%$ com relação a produtos convencionais.

No mercado de produtos orgânicos de origem animal há um grande potencial para a produção de peixes criados em sistemas orgânicos e o Brasil possui características favoráveis para a exploração desse comércio. Todavia, não há informações sobre a formulação, eficiência e o fornecimento de rações orgânicas para peixes, sendo necessários estudos para conhecer a influência destas na alimentação desses organismos.

Contudo, para a formulação da ração orgânica para peixes é imprescindível utilizar ingredientes de origem orgânica e também verificar quais são as substâncias de uso permitido. A relação de substâncias e outros critérios fundamentais a serem seguidos na produção orgânica está presente na instrução normativa 64 do Ministério da Agricultura, Pecuária e Abastecimento (MAPA). No entanto, as normas técnicas para a aquicultura orgânica ainda não estão definidas. O uso de ingredientes que não têm procedência orgânica é permitido em quantidades limitadas, contudo o ingrediente a ser utilizado deve estar presente na lista dos produtos permitidos, como acontece no caso de suplementos vitamínicos e minerais e das farinhas de origem animal.

Portanto, mais estudos devem ser realizados com alimentação, seja de origem animal ou vegetal, com o intuito de fechar um pacote técnico especializado, em que haja uma rede, contemplando os animais e os humanos, havendo alimentos para os animais e, posteriormente, que esses animais sejam fontes alimentícias orgânicas para humanos.

\section{Conclusão}

A substituição da alimentação com ração convencional pela ração orgânica pode ser realizada sem comprometer o desempenho zootécnico dos peixes.

\section{Agradecimentos}

Agradecemos ao convênio 450/2008, firmado entre a Fundação Araucária/Secretaria de Estado da Ciência, Tecnologia e Ensino Superior e o Instituto Água Viva; e ao Grupo de Estudos em Manejo na Aquicultura, pelo apoio e estrutura para realização dos trabalhos. 


\section{Referências}

ARANA, L. V. Princípios químicos da qualidade de água em aqüicultura: uma revisão para peixes e camarões. 2. ed. Florianópolis: Ed. da UFSC, 2004.

BALDISSEROTTO, B.; RADÜNZ NETO,J.Jundiá (Rhamdia sp.). In: BALDISSEROTTO, B.; GOMES, C. L. Espécies nativas para piscicultura no Brasil. Santa Maria: UFSM, 2005. p. 303-319.

BOSCOLO, W. R. et al. Farinha de resíduos da filetagem de tilápias na alimentação de tilápia-do-Nilo (Oreochromis niloticus) na fase de reversão sexual. Revista Brasileira de Zootecnia, v. 34, n. 6, p. 1807-1812, 2005.

COSTA, O. A. D. et al. Índices técnicos dos sistemas intensivo de suínos criados ao ar livre (SISCAL) e confinado (SISCON) nas fases de gestação e lactação. Revista da Sociedade Brasileira de Zootecnia, v. 24, n. 6, p. 953-961, 1995.

DIEMER, O. et al. Sistema integrado de produção de rações orgânicas para utilização na alimentação animal. In: SEMINÁRIO DE EXTENSÃO DA UNIOESTE, 9., 2009, Toledo. Anais... Toledo: Unioeste, 2009.

GODINHO, H. P. Estratégias reprodutivas de peixes aplicadas à aqüicultura: bases para o desenvolvimento de tecnologias de produção. Revista Brasileira de Reprodução Animal, v. 31, n. 3, p. 351-360, 2007.

GOMES, L. C.etal. Biologia do jundiá Rhamdia quelen (Teleostei, Pimelodidae). Ciência Rural, v. 30, n. 1, p. 179-185, 2000.

GUIA RURAL. Manual de agricultura orgânica. São Paulo: Abril, 1991. p. 53-55.

IPARDES. O mercado de orgânicos no Paraná: caracterização e tendências. Curitiba: IPARDES, 2007.

LAZZARI, R. et al. Desempenho e composição dos filés de jundiá (Rhamdia quelen) submetidos a diferentes dietas na fase de recria. Arquivo Brasileiro de Medicina Veterinária e Zootecnia, v. 60, n. 2, p. 477-484, 2008.

LÖSCH, J. A. et al. Fontes de fósforo em rações com certificação orgânica para juvenis de tilápia do Nilo (Oreochromis niloticus). In: REUNIÃO ANUAL DA SOCIEDADE BRASILEIRA DE ZOOTECNIA, 46., 2009, Maringá. Anais... Maringá: Sociedade Brasileira de Zootecnia, 2009a.

LÖSCH, J. A. et al. Fontes de fósforo em rações orgânicas para alevinos de tilápia do Nilo (Oreochromis niloticus). In: REUNIÃO ANUAL DA SOCIEDADE BRASILEIRA DE ZOOTECNIA, 46., 2009, Maringá. Anais... Maringá: Sociedade Brasileira de Zootecnia, 2009b.

LUCHINI, L.; AVENDAÑO, T. Primeros resultados de cultivo de un pez de aguas calidas (Rhamdia sapo) con fines de producción y consumo humano. Revista Argentina de Producción Animal, v. 4, n. 5, p. 621-629, 1985.

MICHALCZYSZYN, M.; GIROTO, J. M.; BORTOLOZO, E. C. Avaliação e certificação em boas práticas de fabricação de uma empresa de alimentos orgânicos no município de Ponta Grossa - PR: estudo de caso. Higiene Alimentar, v. 22, n. 159, p. 33-35, 2008.

ORMOND, J. G. P. et al. Agricultura orgânica: quando o passado é futuro. BNDS Setorial, n. 15, v. 1, 2002, p. 3-34.

SARY, C. et al. Características da carcaça em jundiás (Rhamdia voulę̧) submetidos à alimentação com certificação orgânica e uma comercial. In: SIMPÓSIO INTERNACIONAL DE NUTRIÇÃO E SAÚDE DE PEIXES, 3., 2009, Botucatu. Anais... Botucatu: UNESP, 2009.

SOUZA, M. L. R. et al. Estudo da carcaça do bagre africano (Clarias gariepinus) em diferentes categorias de peso. Acta Scientiarum, v. 21, n. 3, 1999, p. 637-644.

Recebido: 24/11/2009

Received: $11 / 24 / 2009$

Aprovado: $16 / 08 / 2010$

Approved: 08/16/2010

Rev. Acad., Ciênc. Agrár. Ambient., Curitiba, v. 8, n. 4, p. 381-387, out./dez. 2010 